\title{
Mechanisms and characteristics of mesocarbon microbeads prepared by co-carbonization of coal tar pitch and direct coal liquefaction residue
}

\author{
Bingfeng Yan $^{1,2} \cdot$ Guangyao Wang $^{1,2}$
}

Received: 20 February 2019/Revised: 28 July 2019/Accepted: 3 September 2019/Published online: 14 September 2019

(C) The Author(s) 2019

\begin{abstract}
DCLR-P was prepared by direct coal liquefaction residue (DCLR) with ash removal. In the present experiments, mesocarbon microbeads (MCMBs) were prepared by co-carbonization of coal tar pitch (CTP) and DCLR-P. With the increase of DCLR-P content, the yield of MCMBs increased from $47.8 \%$ to $56.8 \%$. At the same time, the particle sizes distribution of MCMBs was narrowed, resulting in the decrease of $\mathrm{D}_{90} / \mathrm{D}_{10}$ ratio from 154.88 to 6.53 . The results showed that DCLR-P had a positive effect on the preparation of MCMBs. ${ }^{1}$ H-NMR, FTIR, SEM and XRD were used to analyze the mechanisms and characteristics of MCMBs prepared by co-carbonization of CTP and DCLR-P. The results showed that the Proton Donor Quality Index (PDQI) of DCLR-P was 13.32, significantly higher than that of CTP $(0.83)$. This indicated that DCLR-P had more naphthenic structure than CTP, which leads to hydrogen transferring in polycondensation reaction. The aliphatic structure of DCLR-P can improve the solubility and fusibility of mesophase, thereby making the structure of MCMBs more structured. The microstructure of the graphitized MCMBs had a substantially parallel carbon layer useful for its electrical performance. The performance of graphitized MCMBs as a negative electrode material for Li-ion batteries was tested. The particle sizes, tap density, specific surface area and initial charge-discharge efficiency of graphitized MCMBs met the requirements of CMB-I in GB/T-24533-2009. However, the initial discharge capacity of graphitized MCMB was only $296.3 \mathrm{~mA} \mathrm{~h} \mathrm{~g}^{-1}$ due to the low degree of graphitization of MCMBs.
\end{abstract}

Keywords Mesocarbon microbeads $\cdot$ Direct coal liquefaction residue $\cdot$ Mechanisms $\cdot$ Characteristics

\section{Introduction}

Mesocarbon microbeads (MCMBs) have been recognized as an exceptional precursor of lithium ion battery anode materials due to its uniform size, excellent sphericity, homogeneous shrinkage and unique microstructure (Chang et al. 1999; Alcantara et al. 2000; Wang et al. 2000; Hossain et al. 2003; Imanishi et al. 2008). MCMBs were typically prepared from coal tar pitch (CTP) with some

Bingfeng Yan

yanbingfeng198415@foxmail.com

1 State Key Laboratory of Coal Mining and Clean Utilization, Beijing 100013, China

2 Beijing Research Institute of Coal Chemistry, China Coal Research Institute, Beijing 100013, China additives. It is acknowledged that the microstructure of MCMBs varies with the different additives ( $\mathrm{Li}$ et al. 2005; Zhang et al. 2005; Concheso et al. 2006; Liu et al. 2007; Song et al. 2008), and the microstructure of MCMBs had a great influence on its electrochemical performance (Korai et al. 1996). The microstructure of MCMBs is considered to be global type or Brooks-Taylor type (Bernhauer et al. 1994; Wang et al. 1999) with the polyaromatic molecules approximately parallel to each other and perpendicular to the surface of the sphere, which is suitable for the lithium ion insertion and desertion (Chang et al. 1999; Alcantara et al. 2000; Wang et al. 2000). A lot of researches have been carried out on the effects of different additives, such as carbon black (Korai et al. 1996; Wang et al. 1999), ferrocene (Bernhauer et al. 1994), flake graphite (Li et al. 2002), carbon nanotubes (Wang et al. 2008) and boron 
(Eichner et al. 1996). The effects of different additives on the preparation of MCMBs can be divided into physical effects and chemical effects (Li et al. 2005). The physical effects showed that the additives did not react with polyaromatic hydrocarbons, only affecting the formation of MCMBs physically such as its shape and sizes. Chemical effects showed that the additives can react with polyaromatic hydrocarbons catalytically and accelerate the formation of MCMBs. However, due to different characteristics of chemical additives, the effect mechanisms of chemical additives on the formation of MCMB is also different.

Direct coal liquefaction residue (DCLR) is one of the products in direct coal liquefaction process. It has the properties of high ash, high sulfur, and high aromatics. In order to improve the economic benefits of direct coal liquefaction, it is necessary to provide a method for high value application of DCLR. Similar to CTP, DCLR is also converted from coal. Therefore, DCLR can be used to prepare high value-added carbon materials such as carbon foam (Xiao et al. 2010), carbon fibers (Liu et al. 2015), and MCMBs (Chang 2017). However, Chang (2017) found that since the mesophase spheres are easy to melt during the synthesis, it is difficult to prepare a large number of MCMBs with uniform size by DCLR alone. In this paper, the MCMBs were prepared by CTP in the presence of DCLR, and the effects of DCLR on the formation and characteristics of MCMBs were also studied.

\section{Experimental}

\subsection{Materials}

CTP was chosen from Kailuan (Group) Limited Liability Corporation (Tangshan, China). DCLR was obtained by $0.1 \mathrm{t} \cdot \mathrm{d}^{-1}$ continuous direct coal liquefaction device in China Coal Research Institute (Beijing, China). Before the preparation of MCMB, DCLR needed to remove its ash. The ash-removal DCLR was like CTP, and then was marked as DCLR-P. The properties of CTP and DCLR-P were summarized in Table 1.

CTP and DCLR-P were also analyzed by ${ }^{1} \mathrm{H}-\mathrm{NMR}$. The chemical shift and hydrogen belonging in ${ }^{1} \mathrm{H}-\mathrm{NMR}$ were shown in Table 2, and the results of ${ }^{1} \mathrm{H}-\mathrm{NMR}$ analysis were shown in Table 3. As seen from Table 3, the value of $H_{\beta} /$ $H_{\mathrm{T}}$ of DCLR-P is 0.27 , much higher than that of CTP (0.02). This indicates the DCLR-P has more aliphatic structure than that of CTP. However, the value of $\mathrm{H}_{\mathrm{au}} / \mathrm{C}_{\mathrm{A}}$ of DCLR-P was 0.56 , much lower than that of CTP $(0.61)$, which indicates that the aromatics of DCLR-P have higher degree of condensation of aromatic rings. The value of $f_{N}$ of DCLR-P was 0.05, much higher than that of CTP (0.03), which indicates DCLR-P has more naphthenic structure. The average chain length (marked as L) of DCLR-P was 3.71, much longer than that of CTP (1.22), which means the removal of aliphatic structure of DCLR-P is easier than that of CTP.

\subsection{Preparation of MCMBs}

The CTP with DCLR-P were sealed off in a 1L stainlesssteel reactor within nitrogen atmosphere. The initial pressure was atmospheric pressure. The contents of DCLR-P in raw pitches were $0 \%, 10 \%, 20 \%$ and $30 \%$ in weight. The polycondensation reaction was carried out at $440{ }^{\circ} \mathrm{C}$ for $8 \mathrm{~h}$, and then the mesophase pitch (MP) was obtained. According to the contents of DCLR-P in raw pitches, the mesophase pitches were labelled $\mathrm{MP}_{0}, \mathrm{MP}_{10}, \mathrm{MP}_{20}$, and $\mathrm{MP}_{30}$. MCMBs were separated from MP with the solvents of pyridine and ethanol at $115^{\circ} \mathrm{C}$ for $2 \mathrm{~h}$. The ratio of solvents to mesopahse pitches was 3:1. MCMBs obtained from $\mathrm{MP}_{0}, \mathrm{MP}_{10}, \mathrm{MP}_{20}$, and $\mathrm{MP}_{30}$ were labelled $\mathrm{MCMBs}_{0}$, $\mathrm{MCMBs}_{10}, \mathrm{MCMBs}_{20}$, and $\mathrm{MCMBs}_{30}$ respectively. The graphitized MCMBs were obtained by heat treatment at $1000{ }^{\circ} \mathrm{C}$ for $1 \mathrm{~h}$ under the protection of nitrogen and then up to $2600{ }^{\circ} \mathrm{C}$ without holding under the protection of argon.

Table 1 Properties of CTP and DCLR-P

\begin{tabular}{|c|c|c|c|c|c|c|c|c|c|}
\hline \multirow[t]{2}{*}{ Samples } & \multirow[t]{2}{*}{$\mathrm{SP}^{\mathrm{a}}\left({ }^{\circ} \mathrm{C}\right)$} & \multirow[t]{2}{*}{ Ash $(\%)$} & \multicolumn{5}{|c|}{ Elemental analysis $(\%)$} & \multirow[t]{2}{*}{$\mathrm{TI}^{\mathrm{b}(2)}(\%)$} & \multirow[t]{2}{*}{$\mathrm{QI}^{\mathrm{c}}(\%)$} \\
\hline & & & $\mathrm{C}$ & $\mathrm{H}$ & $\mathrm{N}$ & $\mathrm{S}$ & $\mathrm{C} / \mathrm{H}$ & & \\
\hline CTP & 85 & 0.08 & 91.78 & 4.76 & 1.10 & 0.79 & 1.61 & 13.0 & 1.41 \\
\hline DCLR-P & 107 & 0.01 & 90.97 & 5.44 & 0.83 & 0.09 & 1.39 & 4.1 & 3.99 \\
\hline
\end{tabular}

Note ${ }^{\text {a }} \mathrm{SP}$ is softening point of pitches

${ }^{\mathrm{b}} \mathrm{TI}$ is the insoluble of Toluene

${ }^{\mathrm{c}} \mathrm{QI}$ is the insoluble of Quinoline 
Table 2 Chemical shift and hydrogen belonging in ${ }^{1} \mathrm{H}-\mathrm{NMR}$

\begin{tabular}{|c|c|c|}
\hline Symbol & Hydrogen type & $\begin{array}{l}\text { Chemica } \\
\text { shift }\end{array}$ \\
\hline$H_{\mathrm{A}}$ & Hydrogen attached to aromatic ring & $6.5-9.5$ \\
\hline$H_{\alpha}$ & $\begin{array}{l}\text { Hydrogen attached to first side-chain carbon } \\
\text { adjacent to an aromatic ring }\end{array}$ & $2.1-4.5$ \\
\hline$H_{\beta}$ & $\begin{array}{l}\text { Naphthenic hydrogen or methyl protons two } \\
\text { positions from an aromatic ring or non- } \\
\text { cyclic methylene or methylene protons two } \\
\text { or more positions from an aromatic ring }\end{array}$ & $1.1-2.1$ \\
\hline$H_{\gamma}$ & $\begin{array}{l}\text { Terminal methyl protons of paraffins or alkyl } \\
\text { side-chains three or more positions from an } \\
\text { aromatic ring }\end{array}$ & $0.5-1.1$ \\
\hline$H_{\mathrm{T}}$ & Total hydrogen & \\
\hline
\end{tabular}

\subsection{Characterization}

The elemental analysis of samples was carried out using the Vario Micro cube elemental analyzer. The hydrogen spectra of nuclear magnetic resonance $\left({ }^{1} \mathrm{H}-\mathrm{NMR}\right)$ were recorded on Avance-300 NMR spectrometer using $\mathrm{CDCl}_{3}$ as solvent. Fourier transform infrared spectroscopy (FTIR) spectra were recorded on Nicolet Nexus 470 FTIR spectrometer. The frequency of scattering of each spectrum was 15 times $\mathrm{s}^{-1}$. $\mathrm{KBr}$ discs were prepared in the usual way from very well dried mixtures of about $1 \mathrm{mg}$ sample and $100 \mathrm{mg} \mathrm{KBr}$. The particle sizes of MCMBs were measured with a Malvern-2000 mastersizer using ethanol as dispersion medium. X-ray diffraction (XRD) analysis of the MCMBs was carried out using PANalytical-Empyrean diffractometer with $\mathrm{Cu}$ radiation. The optical textures of samples were observed using ZEISS QlmagerA2 polarizedlight microscope. The samples were embedded in an epoxy resin and polished at the beginning. The scanning electron microscopy (SEM) was carried out using the nanoSEM-

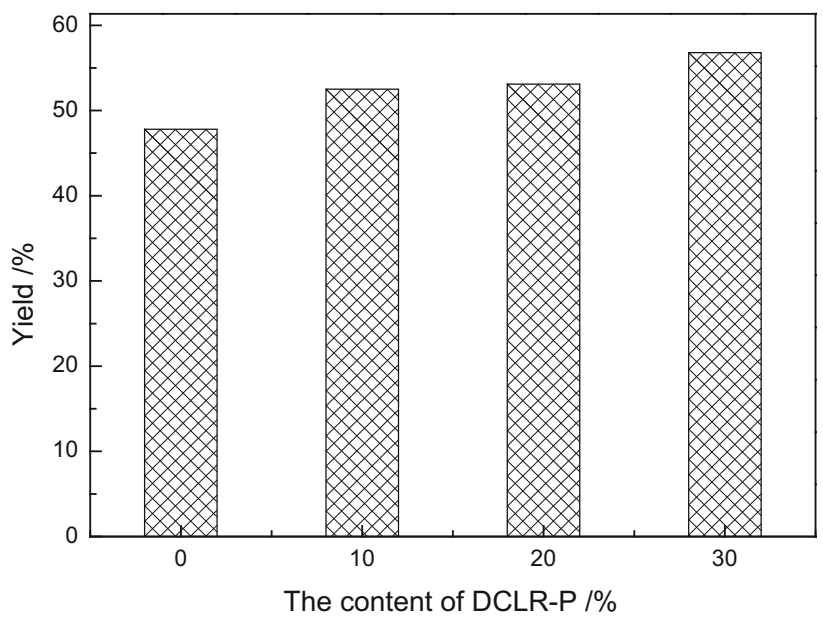

Fig. 1 Yields of MCMBs with different contents of DCLR-P

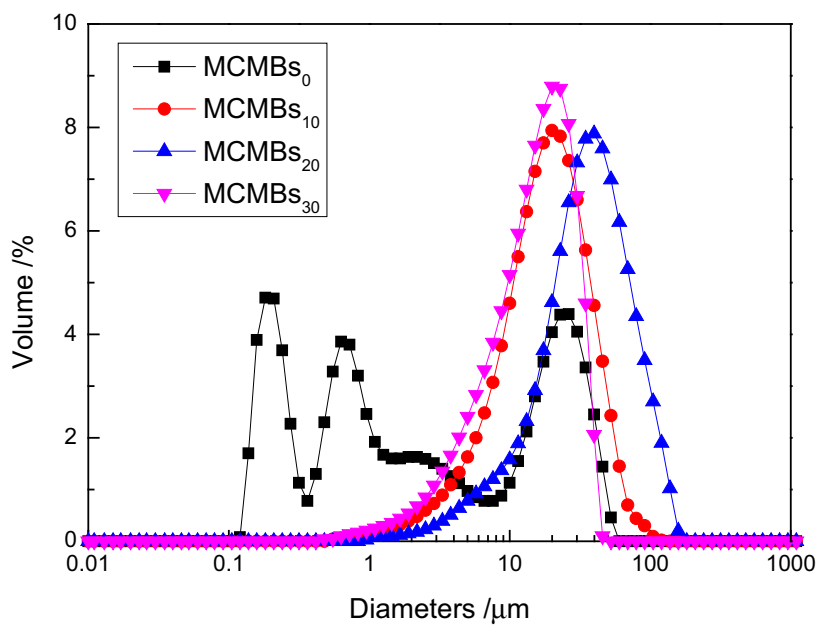

Fig. 2 Particle sizes distribution of MCMBs

Table $3{ }^{1} \mathrm{H}-\mathrm{NMR}$ analysis of CTP and DCLR-P

\begin{tabular}{lllllllllll}
\hline Samples & $H_{\mathrm{A}} / H_{\mathrm{T}}$ & $H_{\alpha} / H_{\mathrm{T}}$ & $H_{\beta} / H_{\mathrm{T}}$ & $H_{\gamma} / H_{\mathrm{T}}$ & $f_{\mathrm{a}}^{\mathrm{a}}$ & $f_{N}^{\mathrm{b}}$ & $f_{p}^{\mathrm{c}}$ & $H_{\mathrm{au}} / \mathrm{C}_{\mathrm{A}}^{\mathrm{d}}$ & $\sigma^{\mathrm{e}}$ & $L^{\mathrm{f}}$ \\
\hline CTP & 0.90 & 0.08 & 0.02 & 0.00 & 0.97 & 0.03 & 0.00 & 0.61 & 0.04 & 1.22 \\
DCLR-P & 0.63 & 0.10 & 0.27 & 0.00 & 0.87 & 0.05 & 0.08 & 0.56 & 0.07 & 3.71 \\
\hline
\end{tabular}

Note ${ }^{\mathrm{a}} f_{\mathrm{a}}$ is the ratio of aromatic carbon to total carbons

${ }^{\mathrm{b}} f_{N}$ is the ratio of naphthenic carbon to total carbons

${ }^{\mathrm{c}} f_{p}$ is the ratio of paraffinic carbon to total carbons

${ }^{\mathrm{d}} H_{\mathrm{au}} / \mathrm{C}_{\mathrm{A}}$ is the degree of condensation of aromatic rings

${ }^{\mathrm{e}} \sigma$ is the degree of subsitution of aromatic rings

${ }^{\mathrm{f}} L$ is the parameter of average chain length, calculated by $\left(H_{\alpha}+H_{\beta}+H_{\gamma}\right) / H_{\alpha}$ 
Table 4 Particle sizes distribution of MCMBs

\begin{tabular}{lcccr}
\hline Samples & $\mathrm{D}_{10}(\mu \mathrm{m})$ & $\mathrm{D}_{50}(\mu \mathrm{m})$ & $\mathrm{D}_{90}(\mu \mathrm{m})$ & $\mathrm{D}_{90} / \mathrm{D}_{10}$ \\
\hline $\mathrm{MCMBs}_{0}$ & 0.180 & 1.668 & 27.879 & 154.88 \\
$\mathrm{MCMBs}_{10}$ & 5.566 & 17.023 & 38.397 & 6.90 \\
MCMBs $_{20}$ & 10.215 & 33.227 & 77.608 & 7.60 \\
MCMBs $_{30}$ & 4.303 & 14.464 & 28.110 & 6.53 \\
\hline
\end{tabular}

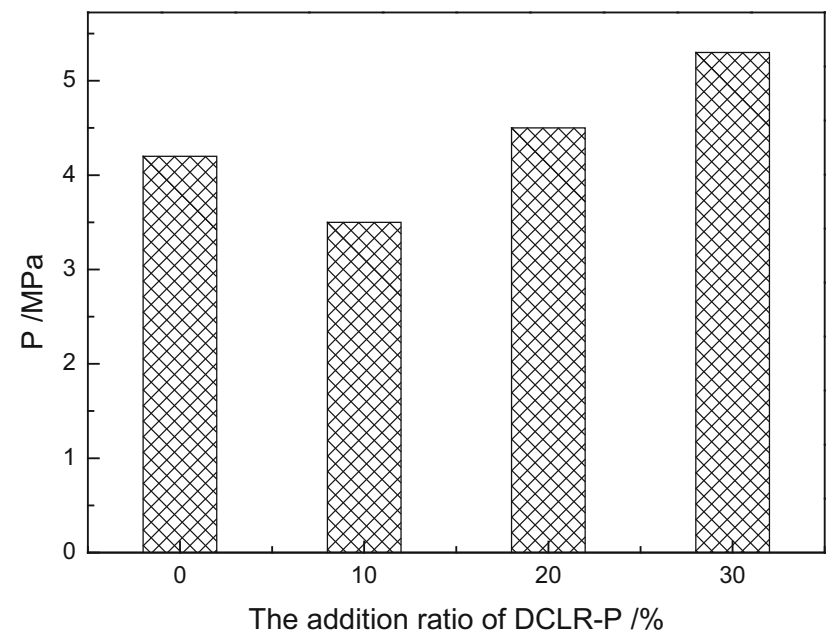

Fig. 3 Variation of terminal pressure with different ratios of DCLR$\mathrm{P}$

450 environmental scanning electron microscope. The MCMBs were coated with aurum in vacuum. The graphitization degree of graphitized MCMBs was characterized using Raman spectrometer (JY-HR800 532 nm).

\section{Results and discussion}

\subsection{Yields and particle sizes of MCMBs}

Figure 1 shows the variation of MCMBs yield with the addition of DCLR-P. It was found that the yield of MCMBs increased with the increase of DCLR-P content. Compared with the yield of MCMBs without DCLR-P added, the yields of MCMBs with 10\%, 20\% and 30\% DCLR-P were from $47.8 \%$ to $52.5 \%, 53.1 \%$ and $56.8 \%$, respectively. This means the addition of DCLR-P has a positive effect on the preparation of MCMBs. Figure 2 and Table 4 show the particle sizes distribution of MCMBs. It was found that the addition of DCLR-P enhanced the sizes of MCMBs. This means that the addition of DCLR-P is helpful for the growth of MCMBs. The ratios of $\mathrm{D}_{90} / \mathrm{D}_{10}$ decreased from 154.88 to $6.90,7.60$, and 6.53 with $10 \%, 20 \%$ and $30 \%$ addition of DCLR-P respectively. This means the particle sizes distribution of MCMBs becomes narrow with

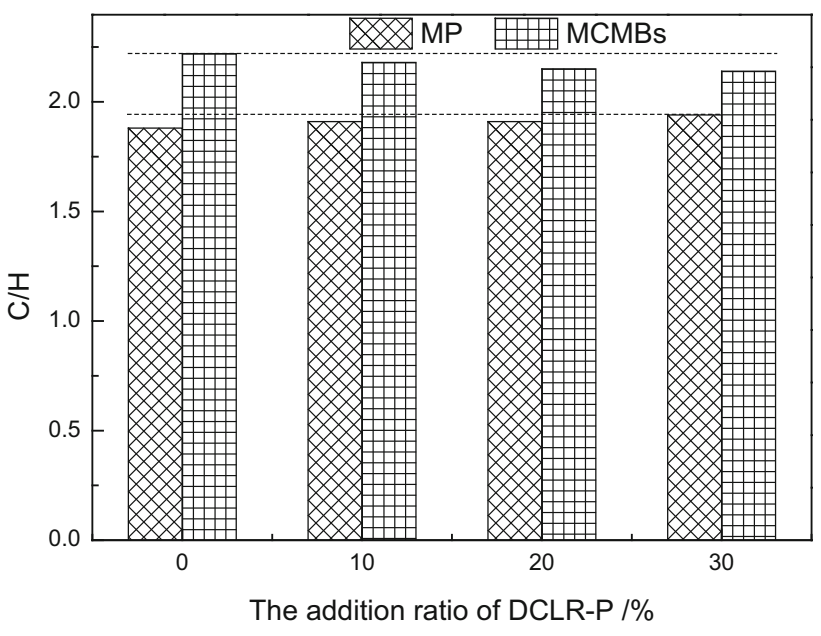

Fig. 4 The ratios of $\mathrm{C} / \mathrm{H}$ of MP and MCMBs with DCLR-P added

the addition of DCLR-P, which is useful to make the size of MCMB uniform.

\subsection{The mechanism of influence on the preparation of MCMBs with DCLR-P added}

Figure 3 shows the variation of terminal pressure of heattreated reaction with DCLR-P added. The terminal pressure decreased with DCLR-P added at first. This indicated that the addition of DCLR-P may inhibit polycondensation reaction of CTP. However, the aromatic rings of DCLR-P had more alkyl side chains than that of CTP, and the average chain length of DCLR-P was longer than that of CTP, so the reactivity of DCLR-P was higher than CTP. Therefore, the addition of DCLR-P may also promote the gas generation, which may lead to the increase of terminal pressure. When the promotion of gas generation exceeded the inhibition of CTP polycondensation, the terminal

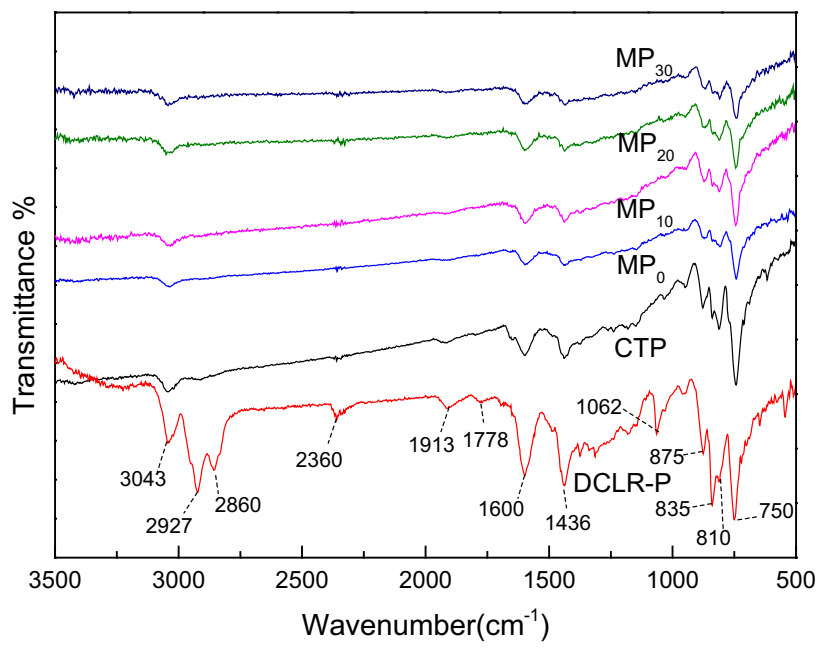

Fig. 5 FTIR spectra of CTP, DCLR-P and MP 
Table 5 Structure parameters of FTIR spectra of DCLR-P, CTP and MP

\begin{tabular}{lclllll}
\hline Samples & $\mathrm{CTP}$ & $\begin{array}{l}\text { DCLR- } \\
\mathrm{P}\end{array}$ & $\mathrm{MP}_{0}$ & $\mathrm{MP}_{10}$ & $\mathrm{MP}_{20}$ & $\mathrm{MP}_{30}$ \\
\hline $\begin{array}{c}\mathrm{A}_{700-900} / \\
\mathrm{A}_{2800-3000}\end{array}$ & 34.80 & 2.28 & 43.22 & 49.47 & 50.67 & 51.62 \\
$\mathrm{~A}_{700-900} / \mathrm{A}_{1600}$ & 8.66 & 5.67 & 7.04 & 8.12 & 6.25 & 6.12 \\
\hline
\end{tabular}

pressure eventually increased with the increase of DCLR-P content.

Figure 4 shows the ratios of $\mathrm{C} / \mathrm{H}$ of MP and MCMBs with DCLR-P added. The ratio of $\mathrm{C} / \mathrm{H}$ of MCMBs decreased with the increase of DCLR-P content. Two explanations were responsible for the result. The first one is that DCLR-P may be involved in the generation of MCMB. The second is that DCLR-P may inhibit polycondensation reaction of CTP because the terminal pressure decreased. However, the ratio of $\mathrm{C} / \mathrm{H}$ of $\mathrm{MP}$ increased with the increase of DCLR-P content, indicating that the addition of DCLR-P may promote the polycondensation reaction of MP, which is helpful to improve the yield of MCMB. Based on the analysis above, the reaction effect of CTP and DCLR-P is better than that of CTP, so there exists a synergistic effect between CTP and DCLR-P in the heattreated process.

The FTIR spectra of CTP, DCLR-P and MP are shown in Fig. 5. The peak-fitting information of samples was obtained through peak-fitting analysis, and the structure parameters of FTIR spectra of DCLR-P, CTP and MP are shown in Table 5. As shown in Fig. 5, the FTIR spectrum of DCLR-P was different from that of CTP. The absorption peaks at $1062 \mathrm{~cm}^{-1}, \quad 1778 \mathrm{~cm}^{-1}, \quad 2860 \mathrm{~cm}^{-1}$ and $2925 \mathrm{~cm}^{-1}$ were stronger in DCLR-P than those in CTP, which indicated that there are more $\mathrm{C}-\mathrm{O}-\mathrm{C}, \mathrm{C}=\mathrm{O}$ and $\mathrm{CH}_{2}-$ groups in DCLR-P. Shu and Zhang (2014) and Niu et al. (2017) suggested that the ratio of $700-900 \mathrm{~cm}^{-1}$ aromatic- $\mathrm{CH}$ bending vibration absorption peak area $\left(\mathrm{A}_{700-900}\right)$ to $2800-3000 \mathrm{~cm}^{-1}$ aliphatic-CH stretching vibration absorption peak area $\left(\mathrm{A}_{2800-3000}\right)$ represented the proportion of aromatic hydrogen to aliphatic hydrogen. The ratio can reflect the aromaticity of sample. The calculation results of $A_{700-900} / A_{2800-3000}$ are shown in Table 5. The value of $\mathrm{A}_{700-900} / \mathrm{A}_{2800-3000}$ of $\mathrm{MP}_{0}, \mathrm{MP}_{10}, \mathrm{MP}_{20}$ and $\mathrm{MP}_{30}$ was $43.22,49.47,50.61$ and 51.62 respectively, much higher than that of CTP (34.80) and DCLR-P (2.28). This indicates that the aromaticity of samples increases after polycondensation reaction, and the more addition of DCLR-P results in the higher aromaticity of MP. The calculated results are consistent with the element analysis results of mesophase pitches. The ratio of $700-900 \mathrm{~cm}^{-1}$ aromatic- $\mathrm{CH}$ bending vibration absorption peak area to
$1600 \mathrm{~cm}^{-1}$ aromatic ring $\mathrm{C}=\mathrm{C}$ stretching vibration absorption peak area $\left(\mathrm{A}_{1600}\right)$ represented the proportion of hydrogen in aromatic rings. The higher the proportion of hydrogen is, the lower the condensation degree of aromatic rings is. The value of $\mathrm{A}_{700-900} / \mathrm{A}_{1600}$ of $\mathrm{MP}_{0}, \mathrm{MP}_{10}, \mathrm{MP}_{20}$ and $\mathrm{MP}_{30}$ was $7.04,8.12,6.25$ and 6.12 respectively. This reveals that the degree of condensation of aromatic rings decreases firstly, and then increases. The reduction of condensation degree of aromatic rings confirms that DCLR-P can inhibit polycondensation reaction. This is consistent with the variation of terminal pressure.

Based on the analysis above, the influence mechanisms of adding DCLR-P on the preparation of MCMBs was understood. Because the aliphatic structure of DCLR-P is easier to be removed than that of CTP, the aliphatic structure of DCLR-P was removed first in the pyrolysis process, which leads to the generation of gas and free radicals. Since free radicals are unstable, on the one hand, it may promote the pyrolyzation of CTP into gas and free radicals, then the ratio of $\mathrm{C} / \mathrm{H}$ of $\mathrm{MP}$ increased with the increase of DCLR-P content. On the other hand, the radicals may further polycondense to form macromolecules. The macromolecules may be considered as the crystal nucleus of MCMBs, which may promote the formation of MCMBs. Therefore, with the increase of DCLR-P content, the yield of MCMBs increased. Besides, there may exist hydrogen transferring to inhibit excessive polycondensation, because the ratio of $\mathrm{C} / \mathrm{H}$ of MCMBs and terminal pressure decrease with the addition of DCLR-P. This can be seen from Proton Donor Quality Index (PDQI) which positively reflects the hydrogen donor quality of samples (Wang 2015). The $P D Q I$ is defined as

$P D Q I=H \% \times 10 \times H_{\mathrm{n} \beta} / H_{\mathrm{T}}$

where $H \%$ is the content of hydrogen of sample (mass fraction), which is obtained by elemental analysis, $H_{\mathrm{n} \beta}$ is the hydrogen of chemical shift in 1.5-2.0 ppm in ${ }^{1} \mathrm{H}-\mathrm{NMR}$ Spectrum, and $H_{\mathrm{T}}$ is total hydrogens in ${ }^{1} \mathrm{H}$-NMR Spectrum. The $P D Q I$ of samples is shown in Table 6. As can be seen from Table 6, the $P D Q I$ of CTP was only 0.83 . However, the $P D Q I$ of DCLR-P was 13.32 , which is significantly higher than that of CTP. Meanwhile, the $P D Q I$ of MP with

Table $6 P D Q I$ of samples

\begin{tabular}{lllr}
\hline Samples & $H \%$ & $H_{\mathrm{n} \beta} / H_{\mathrm{T}}$ & $P D Q I$ \\
\hline CTP & 4.76 & 0.02 & 0.83 \\
DCLR-P & 5.44 & 0.24 & 13.32 \\
MP $_{0}$ & 4.13 & 0.03 & 1.06 \\
$\mathrm{MP}_{10}$ & 4.11 & 0.24 & 9.85 \\
$\mathrm{MP}_{20}$ & 4.11 & 0.21 & 8.56 \\
$\mathrm{MP}_{30}$ & 4.05 & 0.24 & 9.54 \\
\hline
\end{tabular}




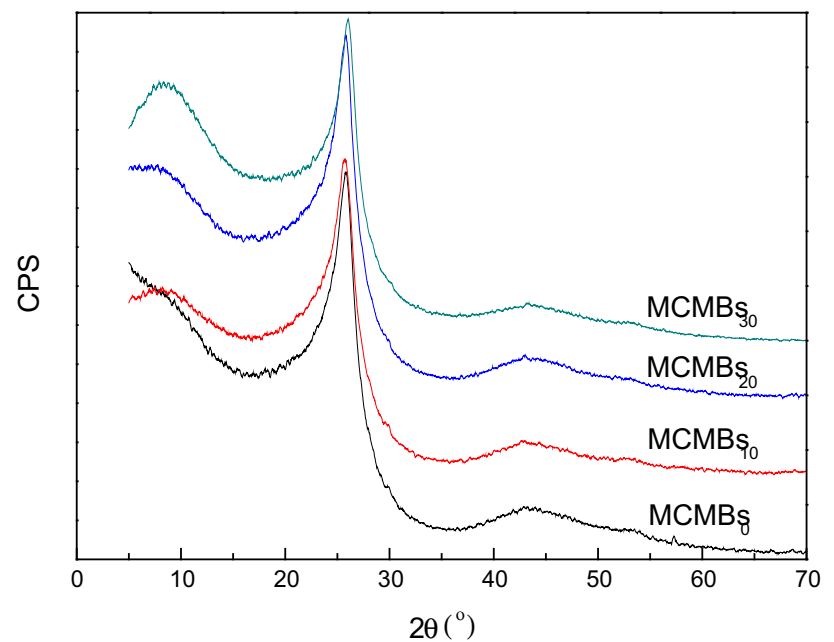

Fig. 6 XRD patterns of MCMBs with DCLR-P added

DCLR-P added ( $>$ 8.56) was much higher than that of MP without DCLR-P added (1.06). This possible deduction is that the hydrogen of $\beta$-methylene and or alicyclic protons of partially hydrogenated polynuclears of the DCLR-P was transferred into the CTP (Tetsuro and Harry 1980).

\subsection{X-ray diffraction analysis}

The XRD patterns of MCMBs are shown in Fig. 6. As can be seen from Fig. 6, the width of the band at half maximum $\left(\beta_{002}\right)$ became smaller with the increase of DCLR-P content and the size of microcrystal of MCMBs became larger. The diameter of the aromatic planar sheet $L_{\mathrm{a}}$ and the height of the crystallite in the c-axis direction $L_{\mathrm{c}}$ can be estimated, using the Bragg and the Warren equations (Bouhadda et al. 2007), from which the following parameters can be extracted.

Inter-sheet distance $d_{002}$ :

$d_{002}=\lambda /\left(2 \times \sin \theta_{002}\right)$

Height of the crystallite $L_{\mathrm{c}}$ :

$L_{c}=0.9 \lambda /\left(\beta_{002} \times \cos \theta_{002}\right)$

Diameter of the sheet $L_{\mathrm{a}}$ :

Table 7 The microstructure parameters of MCMBs

\begin{tabular}{lllllr}
\hline Samples & $2 \theta\left(^{\mathrm{o}}\right)$ & $\beta_{002}\left({ }^{\mathrm{o}}\right)$ & $d_{002}(\mathrm{~nm})$ & $L_{\mathrm{c}}(\mathrm{nm})$ & $N$ \\
\hline MCMBs $_{0}$ & 25.88 & 3.092 & 0.3443 & 2.6 & 8.6 \\
MCMBs $_{10}$ & 25.62 & 2.860 & 0.3477 & 2.8 & 9.1 \\
MCMBs $_{20}$ & 26.04 & 2.863 & 0.3422 & 2.8 & 9.2 \\
MCMBs $_{30}$ & 26.24 & 2.663 & 0.3396 & 3.1 & 10.1 \\
\hline
\end{tabular}
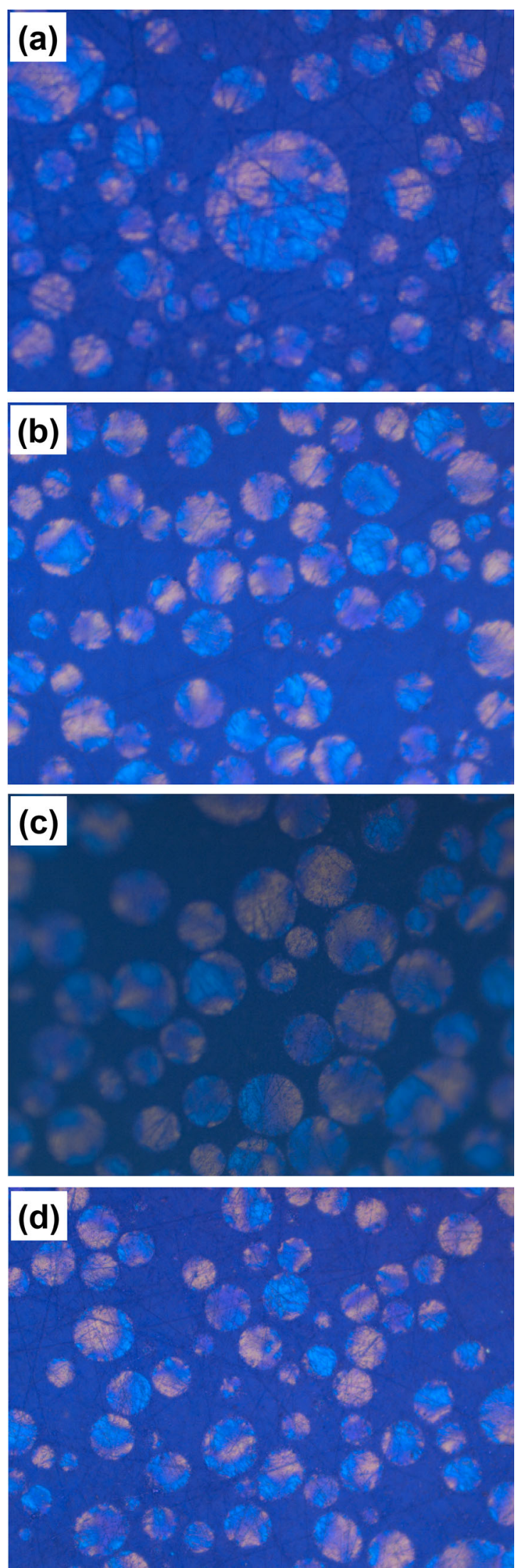
4Fig. 7 Polarized micrographes of MP (× 500) a 0\%, b 10\%, c 20\%, d $30 \%$

$L_{\mathrm{a}}=1.84 \lambda /\left(\beta_{100} \times \cos \theta_{100}\right)$

Average number of sheet per crystallite $N$ :

$N=L_{\mathrm{c}} / d_{002}+1$

Graphitization degree $G$ :
$G=\left(0.3440-d_{002}\right) /(0.3440-0.3354)$

$\beta_{002}$ and $\beta_{100}$ are the widths of the band at half maximum, $\lambda$ is the $\mathrm{X}$-ray wavelength $(0.154 \mathrm{~nm})$ and $\theta$ is the diffraction angle. The parameters calculated from the XRD patterns are listed in Table 7. As can be seen from Table 7, $d_{002}$ decreased from $0.3443 \mathrm{~nm}$ for $\mathrm{MCMBs}_{0}$ to $0.3396 \mathrm{~nm}$ for $\mathrm{MCMBs}_{30}$. This indicated that the layers of microcrystal became flatter. $L_{\mathrm{c}}$ and $N$ became larger with the increase of DCLR-P content. All these changes of the parameters proved that the addition of DCLR-P is useful to make
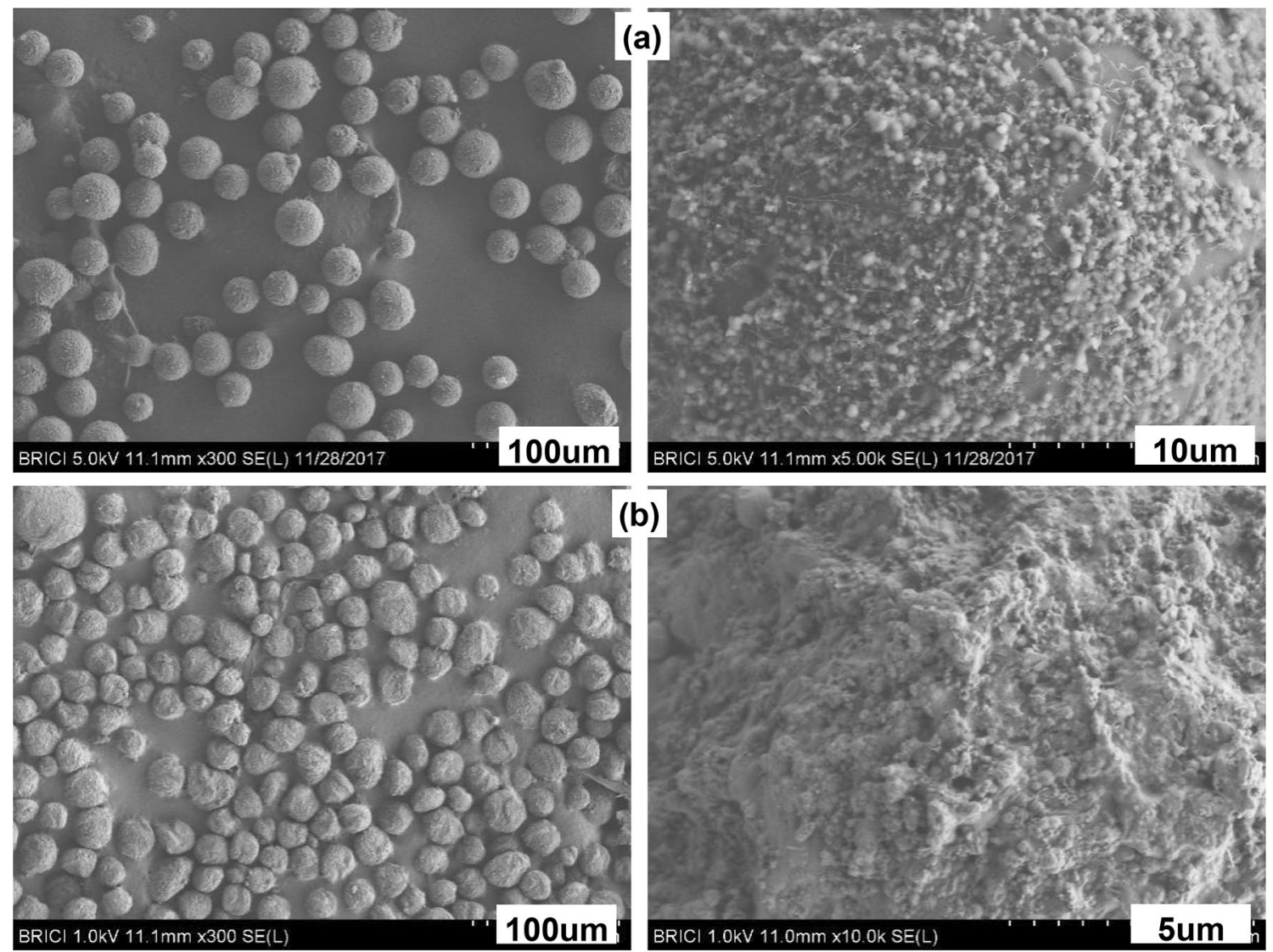

(b)

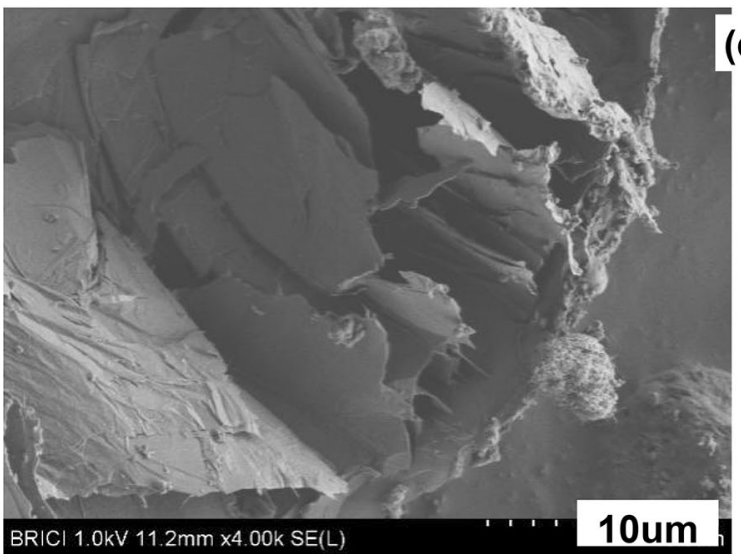

(c)

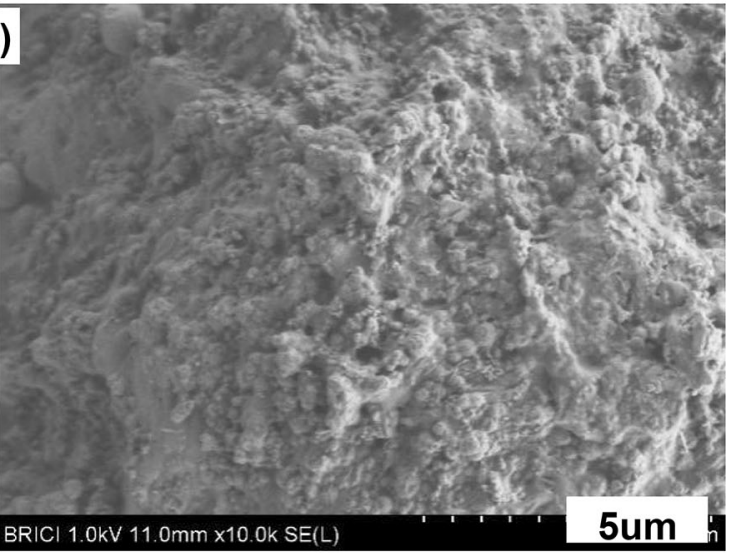

5um

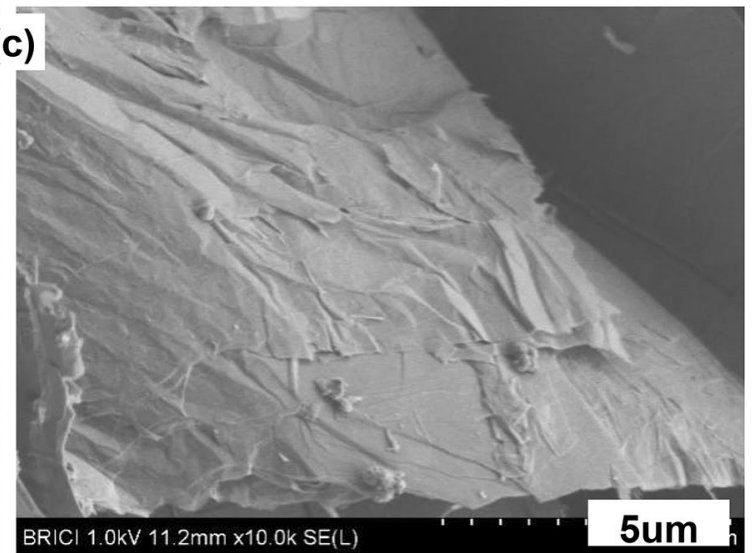

Fig. 8 SEM micrographs of $\mathrm{MCMBs}_{10}$ and graphitized $\mathrm{MCMBs}_{10}$ a $\mathrm{MCMBs}_{10}$. b, $\mathbf{c}$ graphitized $\mathrm{MCMBs}_{10}$ 
Table 8 The performance of graphitized $\mathrm{MCMBs}_{10}$ as a negative electrode material

\begin{tabular}{|c|c|c|c|c|c|c|c|c|c|c|}
\hline \multirow[t]{2}{*}{ Samples } & \multicolumn{4}{|c|}{ Particle sizes } & \multirow[t]{2}{*}{$\rho^{\mathrm{a}}\left(\mathrm{g} \cdot \mathrm{cm}^{-3}\right)$} & \multirow[t]{2}{*}{$\rho^{\mathrm{b}}\left(\mathrm{g} \cdot \mathrm{cm}^{-3}\right)$} & \multirow[t]{2}{*}{$F^{\mathrm{c}}(\%)$} & \multirow[t]{2}{*}{$S S A^{\mathrm{d}}\left(\mathrm{m}^{2} \cdot \mathrm{g}^{-1}\right)$} & \multirow[t]{2}{*}{$C^{\mathrm{e}}\left(\mathrm{mA} \cdot \mathrm{h} \cdot \mathrm{g}^{-1}\right)$} & \multirow[t]{2}{*}{$E^{\mathrm{f}}(\%)$} \\
\hline & $\mathrm{D}_{10}$ & $\mathrm{D}_{50}$ & $\mathrm{D}_{90}$ & $\mathrm{D}_{\max }$ & & & & & & \\
\hline MCMBs & 15.9 & 23.1 & 33.7 & 51.8 & 1.39 & 2.2079 & 99.91 & 0.43 & 296.3 & 94.53 \\
\hline CMB-I ${ }^{\mathrm{g}}$ & $15 \pm 2$ & $22 \pm 2$ & $31 \pm 3$ & $\leq 70$ & $\geq 1.3$ & $2.24 \pm 0.02$ & $\geq 99.95$ & $0.7 \pm 0.3$ & $\geq 340$ & $\geq 94.0$ \\
\hline
\end{tabular}

Note ${ }^{\mathrm{a}} \rho$ is tap density

${ }^{\mathrm{b}} \rho$ is true density

${ }^{\mathrm{c}} F$ is fixed carbon

${ }^{\mathrm{d}} \mathrm{SSA}$ is specific surface area

${ }^{\mathrm{e}} \mathrm{C}$ is initial discharge capacity

${ }^{\mathrm{f}} E$ is initial charge-discharge efficiency

${ }^{\mathrm{g}} \mathrm{CMB}-\mathrm{I}$ is MCMBs conforming to national standard of GB/T-24533-2009

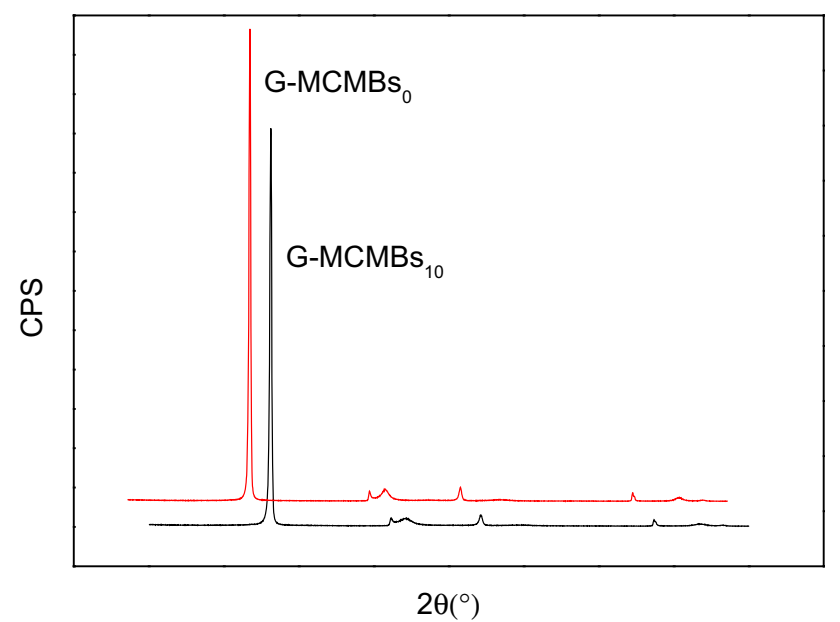

Fig. 9 XRD patterns of graphitized $\mathrm{MCMBs}_{0}$ and $\mathrm{MCMBs}_{10}$

MCMBs structure more ordered. A possible deduction is that the addition of DCLR-P makes the mesophase contain more aliphatic structure. The aliphatic structure can enhance the solubility and fusibility of mesophase (Song et al. 1992). This may lead to the structure of MCMBs more structured.

\subsection{Morphologies of MCMBs and graphitized MCMBs}

Figure 7 shows the optical textures of MP. From the photographs, Fig. 7a shows the sizes of MCMBs are not very uniform. However, the addition of DCLR-P makes the sizes of MCMBs uniform. The sizes of MCMBs increased at first, and then decreased with the increase of DCLR-P content. This is consistent with the results of particle sizes distribution of MCMBs in Fig. 2 and Table 4. The explanation of sizes changes of MCMBs may be as follows. On one hand, DCLR-P is used as a nucleating agent to promote the formation of MCMBs (Yang et al. 2011). On the other hand, DCLR-P also may reduce the system viscosity because DCLR-P has more aliphatic structure than CTP (Song et al. 1992). Both of these contribute to the development of MCMBs. Therefore, the yields and sizes of MCMBs increase with the increase of DCLR-P content (as shown in Fig. 7b, c). When the content of DCLR-P is excessive, it may result in the generation of a large number of crystallite at the beginning of polycondensation reaction. This may soon lead to the production of large quantities of MCMBs, which can be deduced from the increasing of MCMBs. However, the crystallites growing to MCMBs need to absorb matrices from the system, therefore there exists serious competition among crystallites. Besides, a large number of MCMBs occurred may make the viscosity of system. Both of these are not conducive to the increase of MCMBs sizes.

The SEM micrographs of $\mathrm{MCMBs}_{10}$ and graphitized $\mathrm{MCMBs}_{10}$ were shown in Fig. 8. The MCMBs 10 had homogeneous size and excellent sphericity. However, the surface of $\mathrm{MCMBs}_{10}$ was rough with some small particles, which may be the building units of MCMBs. The morphology of the graphitized $\mathrm{MCMBs}_{10}$ were shown in Fig. 8b. The sphericity of graphitized $\mathrm{MCMBs}_{10}$ becomes poor, and the surface of graphitized $\mathrm{MCMBs}_{10}$ was rougher than that of $\mathrm{MCMBs}_{10}$, which may be caused by the escape of small molecule and aromatic condensation in $\mathrm{MCMBs}_{10}$. The inner structure of graphitized $\mathrm{MCMBs}_{10}$ was shown in Fig. 8c. The microtextural carbon layers of graphitized $\mathrm{MCMBs}_{10}$ were approximately parallel to each other, which is useful for its electrical performance.

\subsection{The performance of graphitized $\mathrm{MCMBs}_{10}$ as a negative electrode material for $\mathrm{Li}$-ion batteries}

According to the national standard of China (GB/T-245332009), the performance of graphitized $\mathrm{MCMBs}_{10}$ as a 
Table 9 Microstructure parameters of MCMBs

\begin{tabular}{|c|c|c|c|c|c|c|c|c|c|}
\hline Samples & $2 \theta_{002}\left(^{\circ}\right)$ & $\beta_{002}\left(^{\circ}\right)$ & $d_{002}(\mathrm{~nm})$ & $L_{\mathrm{c}}(\mathrm{nm})$ & $2 \theta_{100}\left({ }^{\circ}\right)$ & $\beta_{100}\left({ }^{\circ}\right)$ & $L_{\mathrm{a}(100)}(\mathrm{nm})$ & $N$ & $G(\%)$ \\
\hline G-MCMBs $\mathrm{s}_{0}^{\mathrm{a}}$ & 26.36 & 0.251 & 0.3382 & 32.17 & 42.30 & 0.38 & 45.99 & 96.14 & 67.91 \\
\hline G-MCMBs b & 26.28 & 0.285 & 0.3391 & 28.33 & 42.27 & 0.48 & 36.01 & 84.53 & 56.44 \\
\hline G-MCMBs ${ }^{c}$ & 26.47 & 0.320 & 0.3363 & 25.38 & 43.85 & 0.31 & 56.67 & 76.53 & 89.53 \\
\hline
\end{tabular}

Note ${ }^{\mathrm{a}} \mathrm{G}-\mathrm{MCMBs}_{0}$ is graphitized $\mathrm{MCMBs}_{0}$

${ }^{\mathrm{b}} \mathrm{G}-\mathrm{MCMBs}_{10}$ is graphitized $\mathrm{MCMBs}_{10}$

${ }^{\mathrm{c}} \mathrm{G}-\mathrm{MCMBs}$ obtained from the reference (Cheng et al. 2009)

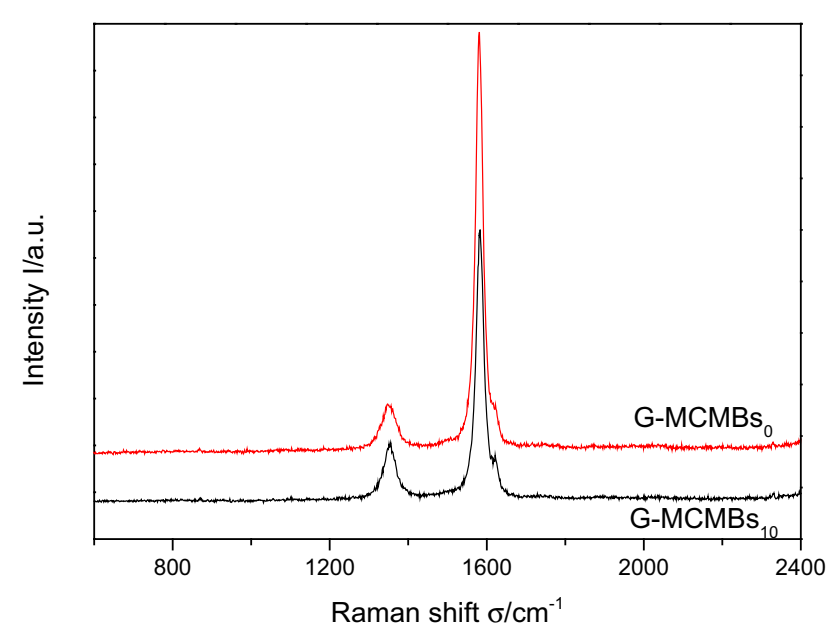

Fig. 10 Raman Spectra of graphitized $\mathrm{MCMBs}_{0}$ and $\mathrm{MCMBs}_{10}$

negative electrode material for $\mathrm{Li}$-ion batteries was tested. The results were shown in Table 8. The particle sizes, tap density, specific surface area and initial charge-discharge efficiency of graphitized $\mathrm{MCMBs}_{10}$ met the requirements of CMB-I respectively. The true density and fixed carbon of graphitized MCMBs 10 were $2.2079 \mathrm{~g} \cdot \mathrm{cm}^{-3}$ and $99.91 \%$ respectively, slightly lower than that of CMB-I. But the initial discharge capacity of graphitized $\mathrm{MCMBs}_{10}$ was $296.3 \mathrm{~mA} \mathrm{~h} \mathrm{~g}^{-1}$, much lower than that of CMB-I ( $\left.\geq 340\right)$. The low initial discharge capacity of graphitized MCMBs 10 may be caused by low graphitization degree of graphitized $\mathrm{MCMBs}_{10}$ (Mabuch et al. 1995; Li et al. 1999; Xu et al. 2003). The graphitization degree can be measured by XRD analysis and Raman Spectra. The XRD patterns of graphitized $\mathrm{MCMBs}_{10}$ and $\mathrm{MCMBs}_{0}$ were shown in Fig. 9. The parameters calculated from the XRD patterns are listed in Table 9. From the XRD analysis, the graphitization degree of graphitized $\mathrm{MCMBs}_{10}$ was $56.44 \%$, which was lower than that of $\mathrm{MCMBs}_{10}(67.91 \%)$ and the reference (89.53\%) (Cheng et al.2009). Meanwhile, the Raman Spectra of graphitized $M C M B s_{10}$ and $\mathrm{MCMBs}_{0}$ were shown in Fig. 10. Two distinct bands centered at
$1360 \mathrm{~cm}^{-1}$ and $1580 \mathrm{~cm}^{-1}$ and The band centered at $1360 \mathrm{~cm}^{-1}$ (D-band) was assigned to the vibrations of carbon atoms with dangling bonds for the in-plane terminations of the defects and disordered graphite (Jawhari et al. 1995; Yang et al. 2010). The band centered at $1580 \mathrm{~cm}^{-1}$ (G-band) was assigned to the vibrations of the $\mathrm{sp}^{2}$-bonded carbon phase in a 2-dimensional hexagonal lattice. The integrated intensity ratios of $\mathrm{D}$ to $\mathrm{G}$ band $\left(I_{\mathrm{D}} /\right.$ $I_{\mathrm{G}}$ ), which further reflects the relative disorder and low graphitic crystallinity of graphitized MCMBs, was 0.23 (G$\left.\mathrm{MCMBs}_{10}\right)$ and $0.12\left(\mathrm{G}-\mathrm{MCMBs}_{0}\right)$. The results obtained from Raman spectra also obviously confirm that G-MCMBs 10 has a low graphitization degree and is in good accordance with the results obtained from XRD analysis.

\section{Conclusions}

The mechanisms of influence on the preparation of MCMBs with DCLR-P added were studied. Because of DCLR-P owing more aliphatic and naphthenic structure than CTP, the addition of DCLR-P can inhibit excessive polycondensation of CTP, and facilitates the formation of MCMB and promotes the nucleation and growth of MCMBs. Due to the addition of DCLR-P, the yield of MCMBs increases and the particle sizes are narrowed. Through XRD analysis, the addition of DCLR-P makes $d_{002}$ decrease, and $L_{\mathrm{c}}$ and $N$ become larger, this means the addition of DCLR-P is useful to make MCMBs structure more ordered. As can be seen from the SEM micrographs of the graphitized MCMBs with DCLR-P added, the microstructure of the graphitized MCMB has a substantially parallel carbon layers, which is useful for its electrical performance. The performance of graphitized MCMBs as a negative electrode material for $\mathrm{Li}$-ion batteries was also tested. The particle sizes, tap density, specific surface area and initial charge-discharge efficiency of graphitized MCMBs met the requirements of CMB-I in GB/T-24533-2009. However, the initial discharge capacity 
of graphitized MCMB was only $296.3 \mathrm{~mA} \mathrm{~h} \mathrm{~g}^{-1}$ due to the low degree of graphitization of MCMBs. If the initial discharge capacity of graphitized MCMB could be improved, the graphitized MCMB may be an excellent anode material for $\mathrm{Li}$-ion batteries.

Acknowledgements Supported by National Key Research and Development Program of China (2018YFB0604601) and the Technology Innovation Fund of China coal research institute (2016CX01).

Open Access This article is distributed under the terms of the Creative Commons Attribution 4.0 International License (http://crea tivecommons.org/licenses/by/4.0/), which permits unrestricted use, distribution, and reproduction in any medium, provided you give appropriate credit to the original author(s) and the source, provide a link to the Creative Commons license, and indicate if changes were made.

\section{References}

Alcantara R, Fernanez Madrigal FJ, Lavela P, Tirado JL, Jimenez Mateos JM, Gomez de Salazar C, Stoyanova R, Zhecheva E (2000) Characterisation of mesocarbon microbeads (MCMB) as active electrode material in lithium and sodium cells. Carbon 38:1031-1041

Bernhauer M, Braun M, Hütting KJ (1994) Kinetics of mesophase formation in a stirred tank reactor and properties of the productsV. Catalysis by ferrocene. Carbon 32:1073-1085

Bouhadda Y, Bormann D, Sheu E, Bendedouch D, Krallafa A, Daaou M (2007) Characterization of Algerian Hassi-Messaoud asphaltene structure using Raman spectrometry and X-ray diffraction. Fuel 86:1855-1864

Chang HY (2017) Effects of nucleating agent on properties of mesocarbon microbeads. Coal Convers 40:39-44

Chang YC, Sohn HJ, Ku CH, Wang YG, Korai Y, Mochida I (1999) Anodic performances of mesocarbon microbeads (MCMB) prepared from synthetic naphthalene isotropic pitch. Carbon 37:1285-1297

Cheng YL, Li TH, Li H, Jing DQ, Wang Z (2009) Effects of preoxidation and the temperature of heat temperature on composition and microstructure of MCMB. J Funct Mater 40:962-965

Concheso A, Santamaría R, Menéndez R, Jiménez-Mateos JM, Alcántara R, Lavela P, Tirado JL (2006) Iron-carbon composites as electrode materials in lithium batteries. Carbon 44:1762-1772

Eichner T, Braun M, Hütting KJ (1996) Element-substituted polyaromatic mesophases: I. Boron-substitution with the pyridine-borane complex. Carbon 34:1367-1381

Hossain S, Kim YK, Saleh Y, Loutfy R (2003) Comparative studies of MCMB and $\mathrm{C}-\mathrm{C}$ composite as anode for lithium-ion battery systems. Power Sources 114:264-276

Imanishi N, Ono Y, Hanai K, Uchiyama R, Liu Y, Hirano A, Takeda Y, Yamamoto O (2008) Surface-modified meso-carbon microbeads anode for dry polymer lithium-ion batteries. Power Sources 178:744-750

Jawhari T, Roid A, Casado J (1995) Raman spectroscopic characterization of some commercially available carbon black materials. Carbon 33:1561-1565

Korai Y, Wang YG, Yoon SH, Ishida S, Mochida I (1996) Preparation of meso-carbon microbeads with uniform diameter from ARisotropic pitch in the presence of carbon black. Carbon 34:1156-1159
Li BH, Lu YG, Liang LC, Liu L, Wu D (1999) Charge-discharge properties of the mesocarbon microbeads for the anods of Lithium ion batteries. New Carbon Mater 14:28-33 (in Chinese)

Li TQ, Wang CY, Liu XJ, Zheng JM, Wang H (2002) Influence of flake-like graphite on the microtexture of mesocarbon microbeads. New Carbon Mater 17:1-6 (in Chinese)

Li TQ, Wang CY, Liu XJ, Zheng JM, Wang H (2005) Characteristics of mesocarbon microbeads generated from a coal tar pitch with addition of micro-alumina powder. Fuel Process Technol 87:77-83

Liu ZJ, Guo QG, Song JR, Liu L (2007) Effect of Ti dopant on shrinkage and performance of MCMB-derived carbon laminations. Carbon 45:146-151

Liu JQ, Gong XY, Zheng DF, Sheng Y et al (2015) Mesophase pitch based carbon fiber prepared from direct coal liquefaction residue. J Funct Mater S2(46):176-180

Mabuch A, Tokmitsu K, Fujimoto H et al (1995) Charge-discharge characteristics of MCMB heat-treated at different temperatures. Electrochem Soc 142:1041-1046

Niu ZS, Wang YG, Shen J et al (2017) Solubitility of a coal tar pitch and distribution of polycyclic aromatic hydrocarbons in soluble portion. J China Coal Soc 42:1311-1318

Shu GP, Zhang YZ (2014) Research on the maceral characteristics of Shenhua coal and efficient and directional direct coal liquefaction technology. Int J Coal Sci Technol 1:46-55

Song HH, Liu L, Wang MZ (1992) Study on the crystal structure and solubility of co-carbonized mesophase pitches. Carbon Tech 3:6-11

Song YZ, Li SZ, Zhai GT, Shi JL, Guo QG, Liu L, Xu ZH, Wang JS (2008) Mechanical and physical properties of MWCNT/carbon composites with matrix derived from mesocarbon microbeads. Carbon 46:1100-1102

Tetsuro Y, Harry M (1980) ${ }^{1}$ Hn.m.r. study of the co-carbonization of hydrogenated anthracene oil with coal-tar and coal. Fuel 59:362-364

Wang GY (2015) Study on hydrogenation reaction activity of Badaowan coal with coal tar. China Coal Research Institute, Beijing, pp 49-50

Wang YG, Egashira M, Ishida S, Korai Y, Mochida I (1999) Microstructure of mesocarbon microbeads prepared from synthetic isotropic naphthalene pitch in the presence of carbon black. Carbon 37:307-314

Wang CY, Jiang H, Li P, Zheng JM (2000) Structure of mesocarbon microobeads formed with original QI as seed crystal. New Carbon Mater 15:9-12 (in Chinese)

Wang Z, Wu B, Gong QM, Song HH, Liang J (2008) In situ fabrication of carbon nanotube/mesocarbon microbead composites from coal tar pitch. Mater Lett 62:3585-3587

Xiao N, Zhou Y, Qiu JS et al (2010) Preparation of carbon nanofibers/carbon foam monolithic composite from coal liquefaction residue. Fuel 89:1169-1171

Xu ZY, Yin ZL, Xie H, Zhu P et al (2003) The influence of HTTmax on performance of C-MCMB. Battery Bimon 33:8-11

Yang YZ, Liu XG, Luo QP, Jin L, Xu BS (2010) Structure evolution of carbon microspheres from solid to hollow. New Carbon Mater 25:431-437 (in Chinese)

Yang YJ, Lin QL, Huang YQ, Guo DY (2011) Efficient preparation of mesocarbon microbeads by pyrolysis of coal-tar pitch in the presence of rosin. J Anal Appl Pyrol 91:310-315

Zhang LJ, Zhao XB, Xia DG (2005) Electrochemical properties of $\mathrm{CoSb}_{3}(-\mathrm{MCMB})$ anodes for lithium-ion batteries. Mater Lett 59:3448-3451 